\title{
Pros and Cons of the Renewable Energy Application
}

\section{Péter Kádár}

Power System Department Faculty of Electrical Engineering, Óbuda University, Bécsi út 96/B, H-1034 Budapest, Hungary

e-mail: kadar.peter@kvk.uni-obuda.hu

\begin{abstract}
Nobody questions the reason for existence of fossil power plants meanwhile the acceptance of the renewable tools is often problematic. Of course the rationales based on the experiences of decade long operation the picture is not clear. The world turns to the consciousness that well-ruled renewables contribute to the sustainability. We summarize dozens of pros and cons and we are going to suggest ways to fit the renewable resources into the power system.
\end{abstract}

Keywords: power system, renewable sources, integration to the power mix

\section{Introduction}

Immanuel Kant in his work „The Critique of Pure Reason” [1] had two controversial logical statements. He proved both of them right by pure logic. One is deduced on the left side page of his work the other on the right side page. It shows that the perception of the real word is done in different ways and only the logical (and honest) thinking don't obviously arrive at the unique conclusion. This dual situation characterizes the application of the renewable energies, too. These techniques move into the mature phase, there is not too much doubt about the operation. The long term effects are not yet cleared and this provides the basis for the eternal debate. Almost all the assumptions are reasonable, only the conclusion differs if they are good or not for our future. In the following presentation we describe a set of pros and cons of the most widely used renewable resources. Looking for the optimal power generation is a standard problem of energy policy. [2-8] 


\section{Hydro Energy}

The hydro power application is one of the oldest technical solutions. For electricity generation it has been used almost for 140 years. During these years a huge amount of knowledge was accumulated. Through the construction and operation of the more than 100.000 establishments nearly all the possibilities and contingencies were experienced. There are no surprises all the effects can roughly be forecast. The hydro complex consists of the hydro power station and waterway/reservoir in large extension, e.g. dams. It is in the focus of debates.

\section{Advantages of the damming}

- Renewable energy source

- The operation is $\mathrm{CO}_{2}$ free (theoretically)

- Energy source comes to the turbine, no external transport is required

- The running water slows down, doesn't wreck the bank

- The environment is not loaded by heat

- The dam can protect areas from flood

- Waterway transport is more secure

- The number of the personnel is low

- Fast starting, easy control

- Black start capability

- Efficiency above $80 \%$

- High lifespan (over 100 years)

- New wild water areas are formed

- Touristic highlights, holiday environments

\section{Risks}

The longer list of the problems comes from the huge number of the detailed analyses of the last hundred years.

- The specific area usage is the worst in case of hydro energy. Large areas are flooded:

○ Sobradinho, Brasil - where 1.050 MW were harvested from 415.000 hectares $-0,25 \mathrm{~W} / \mathrm{m}^{2} !$ !

○ Venezuela Guri complex - where 10.300 MW run on 426.000 hectares $\left.-2,4 \mathrm{~W} / \mathrm{m}^{2}\right)$.

- Balbina, Brasil - where $2500 \mathrm{~km}^{2}$ Amazonian rain forest was flooded for $250 \mathrm{MW}-0,1 \mathrm{~W} / \mathrm{m}^{2}$. It became the symbol of the ecological destruction beyond reason. ${ }^{2}$

- Gabcikovo, Slovakia - where 720 MW was built in with 5300 hectares $-13,5 \mathrm{~W} / \mathrm{m}^{2}$

\footnotetext{
${ }^{1}$ Environmental criteria for site selection of hydroelectric projects, The world Bank, 2003

${ }^{2}$ http://ergobalance.blogspot.com/2007/07/hydro-not-so-green.html
} 
○ Itaipu, Brasil - where $14.000 \mathrm{MW}$ were harvested from 135.000 hectares $-10,3 \mathrm{~W} / \mathrm{m}^{2}$

- The hydro energy is not really $\mathrm{CO}_{2}$ free. In case of careful design the specific emission is low, but we can't forget the iron furnacing and cement burning emission. In a bad case the eutrophication produces million tons of methane. ${ }^{3}$

- If we project all the investment costs to the produced electricity, we get really high specific electricity price (we normally have other purposes too e.g. flood protection, irrigation, shipping, etc.)

- Construction takes 5-15 years

- No protection from flood and drought

- Significant cultural heritage has been devastated by the inundation (e.g. in Aswan, Egypt or at Merowe plant in Sudan. ${ }^{4}$

- An interesting specific number is the displaced persons/MW. At Mozambique/Cabora Bassa - 120 person/MW (total 249.000 persons), in China, Three Gorges -66 person/MW (total 1.200 .000 persons). ${ }^{5}$

- The dams are built with large heading in front of the former waterfalls. The Nile dams tuck away the ancient cataracts, the Iguacu dam the Guaira falls in Brasil ${ }^{6}$.

- Vessel traffic is traversed

- The natural sandy bank is changed into rocky shore. Pay gravel never comes anymore.

- Level of the underground water rising.

- Due to the slowing down of the flow the floating drift subsides

- Beside the headwater channels the floodplains are going to be drained

- Below the dam the riverbed is deepened and the level of the underground water is sinking

- Large agricultural areas are taken out from the food production

- Masses of peoples must be resettled (e.g. China - Three Gorge Dam more than 1,5 millions)

- The peak power operation erodes the bank

- The dynamic water level changes disturb the fish reproduction

- Earthquake, mud sliding and terrorist attacks cause dam break and catastrophe. $^{7}$

- The excavation of the sediment in the upper reservoir hurts the natural drinking water filtering structures

3 Vincent St. Louis: Hydro, not so Green?, Canadian University of Alberta, http://ergobalance.blogspot.com/2007/07/hydro-not-so-green.html

${ }^{4}$ http://www.meroe.hu

${ }^{5}$ IEEE power and energy magazine july/august 2008

${ }^{6} \mathrm{http}: / /$ tourismplacesworld.blogspot.hu/2011/06/guaira-falls-brazil.html

7 Epic Vajont Dam Disaster, Italy, 1963: Manmade or Natural? http://www.semp.us/publications 
- The excavation work produces new sediments that can cover the previously clean gravel.

- The fish don't like the banks covered by concrete or asphalt.

- The shallow water is overheated in summer and the fish may perish

- The wastewater is cleaned biologically and mechanically into the natural rivers. The slow flowing results eutrophication, for enrichment of polluting materials.

- In North Canada in the frame of La Grande/James Bay project $2830 \mathrm{~km}^{2}$ area was flooded. The decaying flooded forests produce toxins that mean high health risk for the aboriginal local Inuit people. ${ }^{8}$

- The damming in the desert (e.g. Nile - Aswan, Egypt or Merowe, Sudan) causes losses in three ways: evaporation in the hot air from the large surface, leaking in the large sandy riverbed and excessive irrigation.

- At high dams the new water level washes hillsides and slip into the water. The wandering wave may break the dam, too.

- An ethical question is the disturbance of aboriginals and the ecology of the flooded area. The eutrophication of the water (decaying forest) pollutes the lake and the drinking water reservoirs.

- Is it really necessary to exploit the renewable energy resources of black Africa (Congo river) and transmit the electricity to the ,developed" Europe?

- Large dams retain the thousand year old water sources: Turkey $<->$ Syria on Euphrates river; USA $<->$ Mexico on Colorado River.

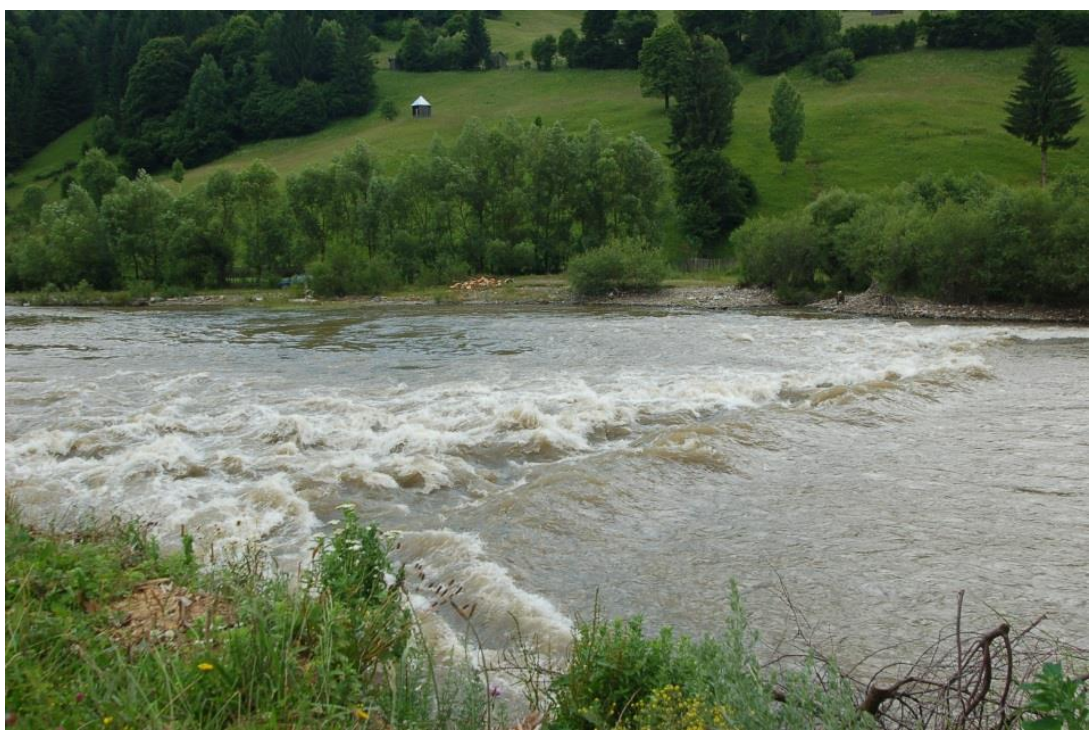

Figure 1. River Bistrica in Romania 2011

\footnotetext{
${ }^{8}$ James Bay - Where two worlds collide; National Geographics - Water 1993 November
} 


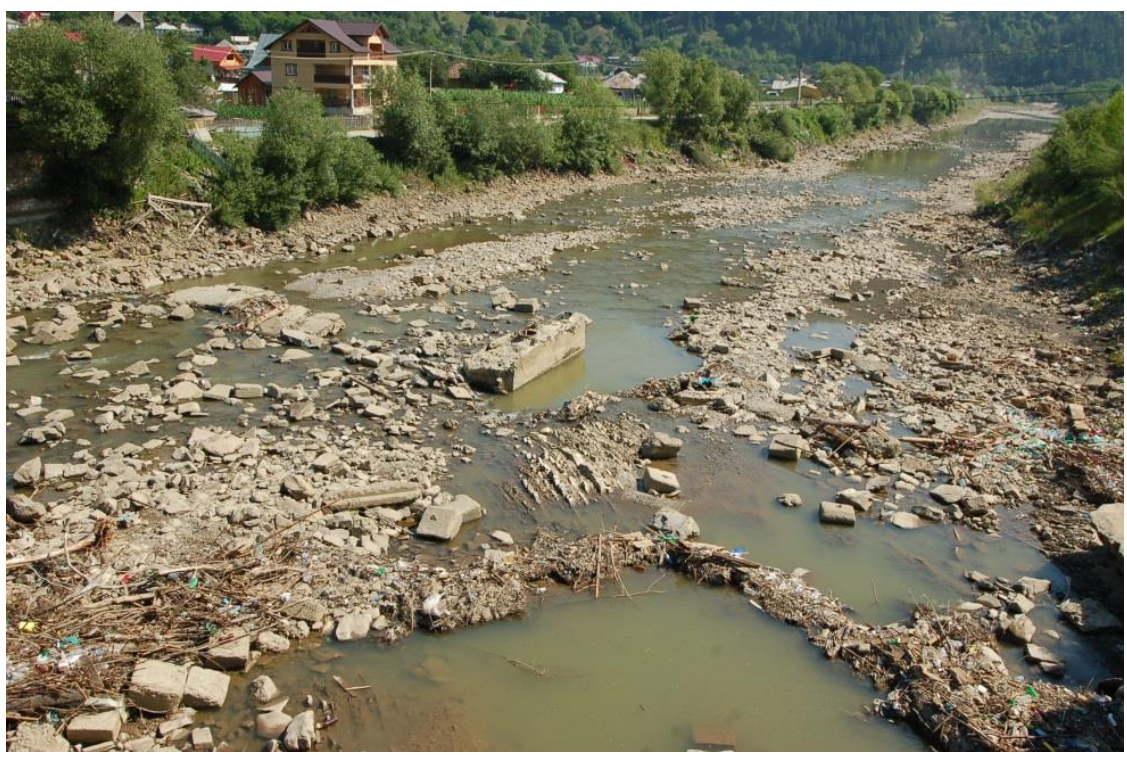

Figure 2. Dried riverbed of deviated Bistrica River in Romania 2011

\section{Wind Energy}

Wind energy application in the last four decades has matured phase. The most widely emphasized pros and cons are the following.

Pros

- renewable energy

- low maintenance cost

- medium (not high) price

- few residual waste materials

Against

- volatile production

- hard to estimate (precisely)

- noise disturbs the environment

- birds are in danger

- drying of the soil

Since the wind application is quotidian practice nowadays more deemed problems and their solutions are known. Here we list some assumed but not real obstacles against wind based energy production. Fortunately there are satisfactory solutions. 
We discuss the sudden loss of wind production (con), some theoretic integration methods and recommended manners. [10]

\subsection{Sudden stops of wind power plants}

\section{Network problem}

As the following record shows $500 \mathrm{MW}$ of wind production dropped suddenly (and resumed to operation). Due to network faults (line, breaker or transformer problem) one or more turbines can be isolated which causes a stop. It is not a specialty of wind generation it can happen to any other plant.

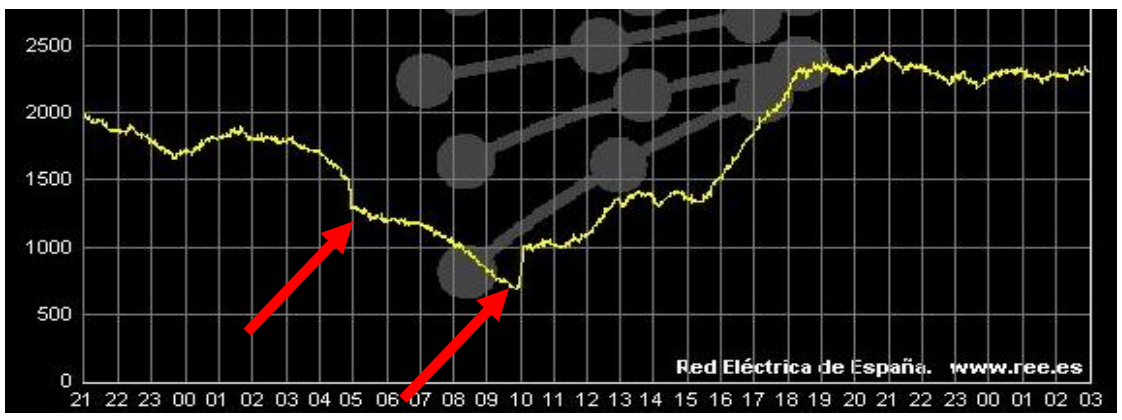

Figure 3. Outage of wind plants for network fault in Spain

\section{Behavior in case of frequency deviation}

The turbines have frequency protections that turn them off in case of underfrequency. It happened on $4^{\text {th }}$ of November 2004 when the European power system split into three parts and the south-West part had under-frequency for the lack of production capacity. Similar protection operates in nuclear power plants, too. Nowadays the new frequency dependent wind turbine control can alleviate the load-frequency balance: in case of over-frequency (over $50 \mathrm{~Hz}$ ) cuts back the output power, on the opposite side produces the appropriate maximum.

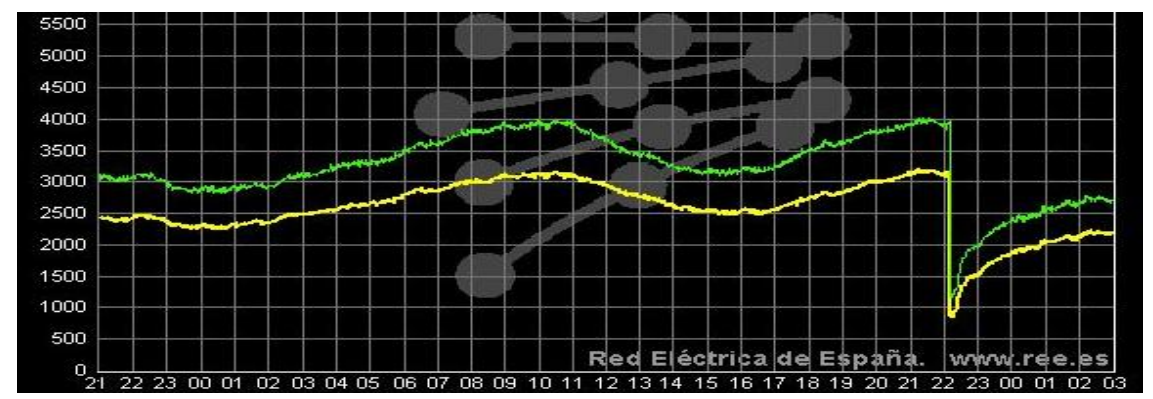

Figure 4. Fall out of wind plants for frequency problems in Spain on 2006.11.04. 


\section{Cut off by storm?}

The individual wind turbine's cut off speed is between $25-30 \mathrm{~m} / \mathrm{s}$. In case of stormy wind each element of the plant makes an emergency stop. The total dropped power can reach some hundreds of MWs. - Is it a real problem to lose 200 MW? - NO. It is a normal daily event to lose any thermal power plant unit up to $1000 \mathrm{MW}$. The power system withstands it. On the other side the stormy weather can be well forecast, so this event doesn't reach the system unprepared.

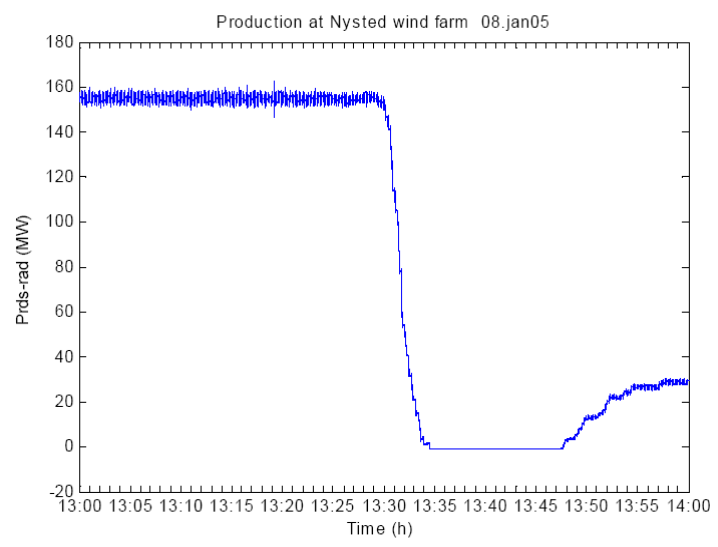

Figure 5. Windpark output during storm in Denmark ${ }^{9}$

\section{Is the pumped storage plant an indispensable need to wind capacities?}

There is an opinion that a high ratio of the hydro plants in the national power mix and/or the pumped storage plants would allow for large scale wind integration. We can state, that these energetic devices make the integration easier, but these are not indispensable elements of the system. Good examples are the German, Danish and the Dutch energy mix. The wind energy can be planned in the day-ahead energy portfolio. The deviation comes from the forecast errors it is generally controlled by oil, gas and coal fired plants, but as a curiosity can we mention that in Germany some nuclear plants participate in the wind generation balancing (e.g. Kernkraftwerk Isar). A Hungarian proposal is to realize small scale Pumped Storage systems too.

\footnotetext{
${ }^{9}$ Joana Rasmussen: System Protection Schemes in Eastern Denmark
} 


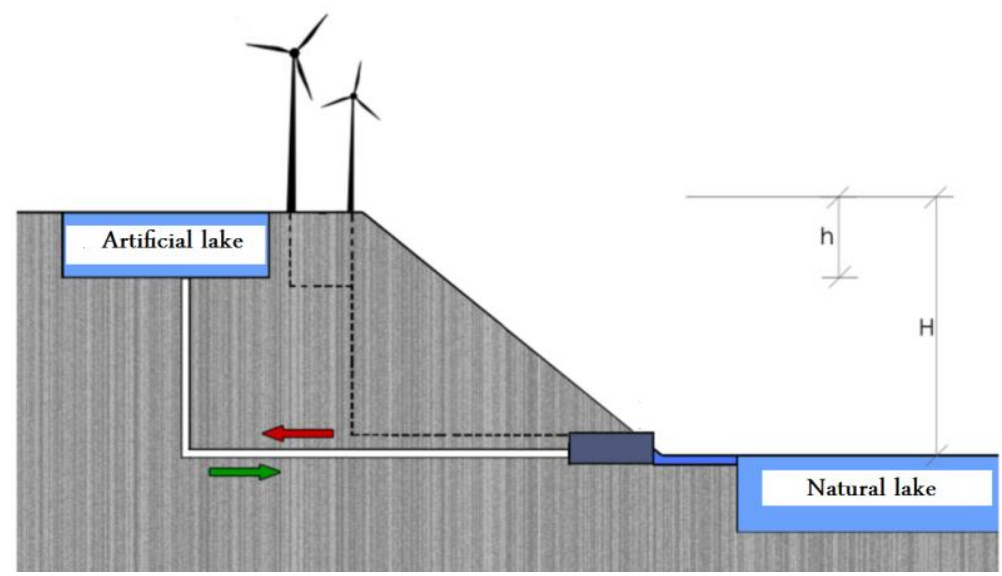

Figure 6. Micro pumped storage plant ${ }^{10}$

\section{Generation volatility}

Due to the steep operation characteristics of the turbines the wind speed changes are amplified in the power output in quadratic measure. The local turbulences equalize each other and the statistical sum of the individual productions is really smooth. The diversification in space helps also this smoothening. In case of bulk plants or branches of plants the individual upload and download gradients are also moderated.

\subsection{Ideal solutions}

Although there are many paper solutions for the integration, not all are viable.

\section{Store the energy in form Hydrogen}

As the load and wind generation peaks are really independent a good idea is to store the wind energy. A classic demonstration was made on Utsira Island in Norway ${ }^{11}$, where the surplus wind energy was converted and stored in form of hydrogen and it was reformed into electricity by fuel cells. The system works, technically it is realistic. The only problem is that the total electrical efficiency of the loop (hydrogen generation, compression, storage, fuel cell, etc.) is not higher than $60 \%$. So it closely doubles the wind energy price - without taking into account the really high investment cost.

\footnotetext{
${ }^{10}$ Courtesy of F\&L Ltd.

${ }^{11}$ The Utsira wind -hydrogen project; IPHE ILC meeting, Rio de Janeiro, March22, 2005;

Presentation on behalf of Hydro -Trygve Riis
} 
A better option is to use the hydrogen directly in traffic by gas engines or by fuelcells. Not only the surplus wind energy but the "early morning valley time" generated energy can be transformed into hydrogen form.

\section{Co-control with gas engines}

The widely used medium size (1-3 MW) cogeneration (CHP) gas engines can be involved in the wind-deviation control. A set of the micro CHPs through virtual power plants (VPP) can be co-controlled too.

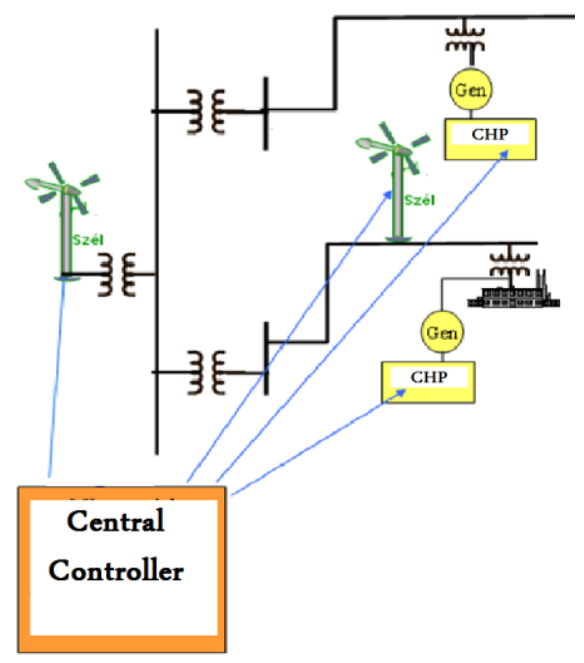

Figure 7. Fig. Co-control of different production characteristics

\section{What capacities can be used for control?}

In the power system more generation/consumption capacity is built in than are usage in a moment (actual power - built power). Almost all elements are controllable but practically only some parts, some large elements are involved into the power balance control. The exploitation and the connection of the up to this time not used control capacities are huge reserves how to balance the non planned deviations. The smart technology helps it. Unfortunately the present control practice is determined by financial interest and contracts that will not be easily changed without hurting interests of actual energy producer. 


\subsection{Real solutions}

\section{The DSM and the Smart grids}

By the traditional paradigm we produce as much energy (power) as we need. We follow the need to have a balance between demand and production. The same result can be reached by controlling demand. The passive and active Demand Side Management (DSM) deals with it. New smart technics broadening the appliances included in this cooperation.

\section{Aggregated control centers}

In the last decade there appeared more and more aggregation centers where the small, non-scheduled, non-controlled rest capacities are handled as a whole. In the power market control centers act jointly, give bids for production, control or 'no run'. This logical solution is supported by developed info communication (smart system) but it was not made specifically for the renewables. It helps the integration (Virtual Power Plant) The VPP helps the work of the system operator, too. One of the earliest solutions is the Control Center for Renewable Energy (CORE), Iberdrola, Toledo, Spain ${ }^{12}$, but there are 4 small VPPs in Hungary too.

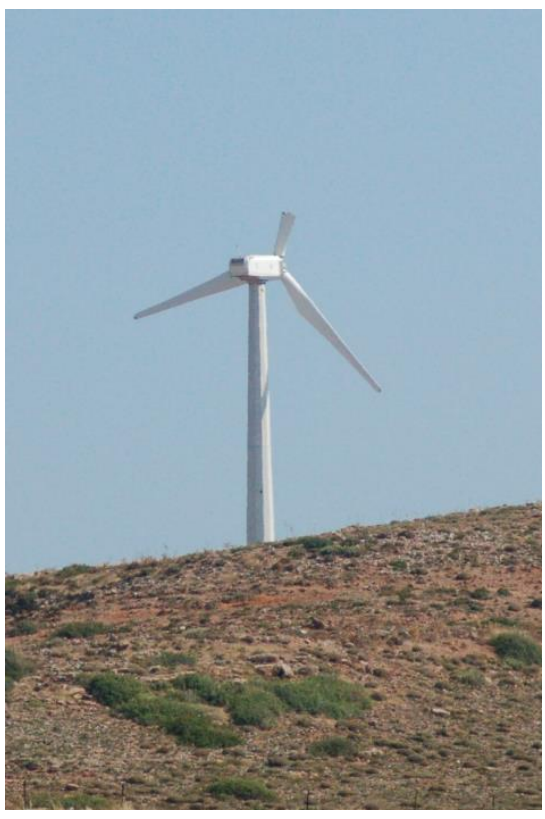

Figure 8. Damaged turbine at Crete, Greece

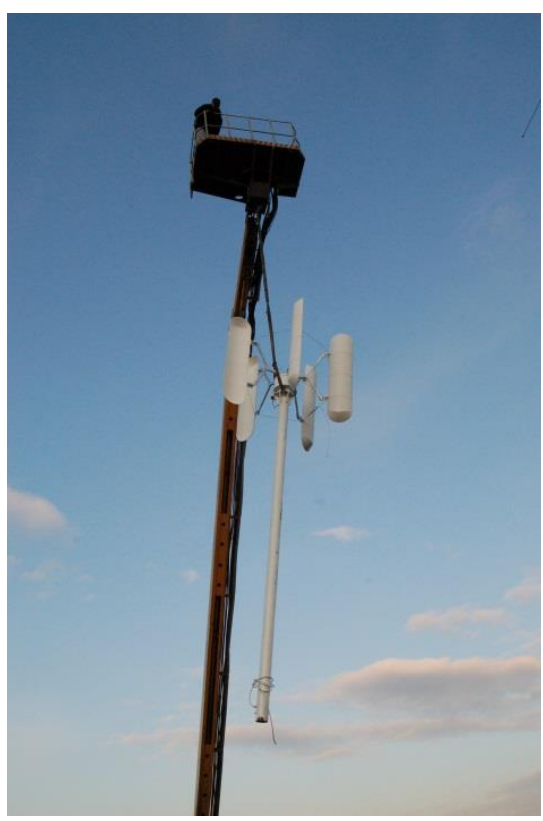

Figure 9. Craning of Vertical Axe Wind Turbine (VAWT) at Óbuda University

12 source: Iberdrola 


\section{The fuel saving approach}

There is no power system based 100 percent on wind generation. The way of the technical development is to set up a system by traditional sources (coal, oil, gas, nuclear). It is followed by the wind and PV extension. The right approach: we have an operating system, and we use less fossil fuel if we have actually renewable production. This is the fuel saving approach. ${ }^{13}$

\section{Photovoltaic solutions}

Electricity production based on solar radiation is not a new idea but spread over only in the last decade. That is why we don't have so many best practices and bad experiences. Main solutions are the semiconductor based photovoltaics (PV) and the mirrored concentrated solar power (CSP). [11-13] Of course we have the procons list:

\section{The advantages}

- renewable energy, no $\mathrm{CO}_{2}$ emission during the operation

- low maintenance cost

- good daily characteristics (peak power generation)

- large industrial halls and „,brown” areas can be reused

- the solar panels shielding against the heat on the roofs

- no noise production

- can be anticipated

\section{Disadvantages}

- $\quad$ high energy pay-back time (a lot of 'built in' energy needed to produce the devices)

- $\quad$ seasonal production (summer - more, winter - less)

- the reflected light is polarized and it victimizes millions of insects and birds. By mistake they take the solar panels for lakes.

- large areas may be used instead of agriculture

- lack of raw materials

- leaking of toxic materials during the semiconductor production

- dangerous waste must be deployed after dismounting the system

- birds can be burned over CSP

- weak mechanical resistance against ice fall in storm

\footnotetext{
${ }^{13}$ source: WWEA 2010
} 


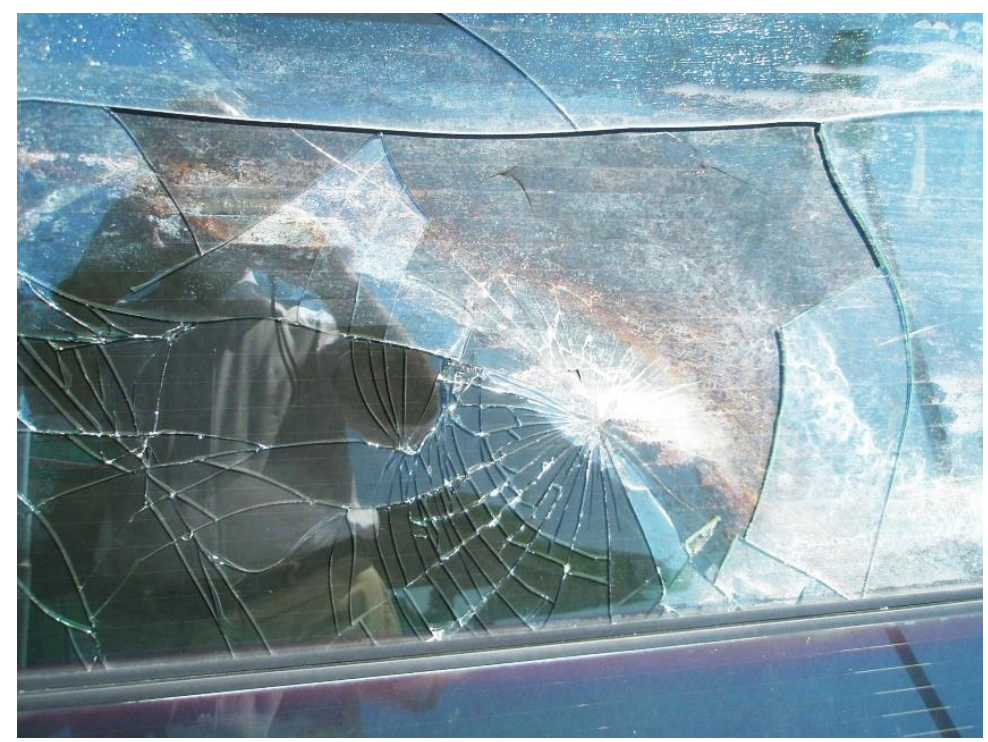

Figure 10. Broken PV amorphous PV panel (2010) ${ }^{14}$

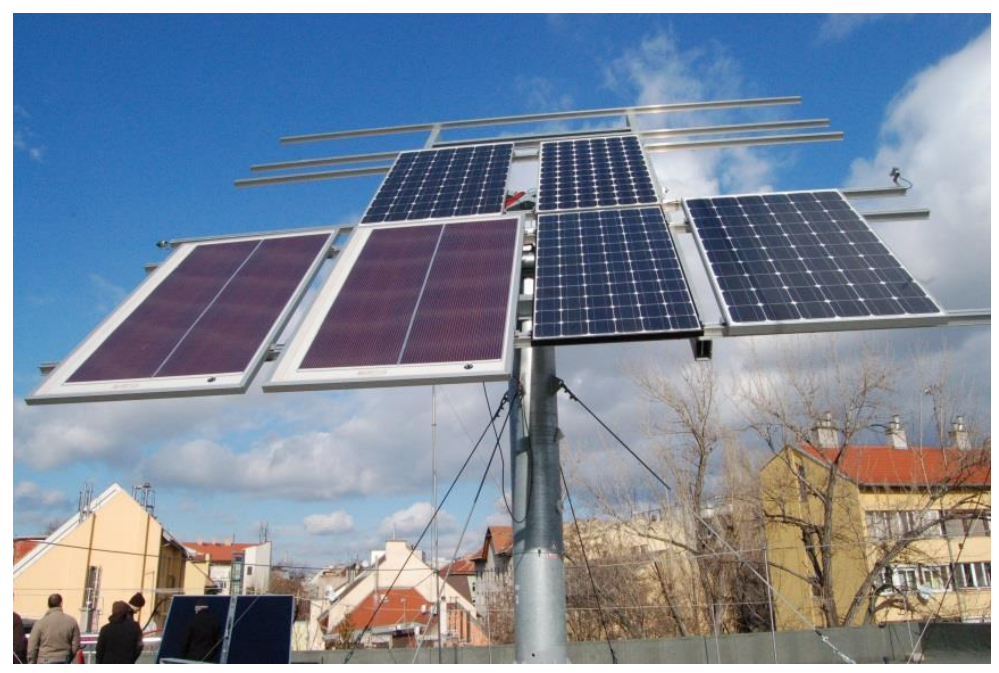

Figure 11. PV panel testing on Sun tracking system at Óbuda University

${ }^{14}$ Photo of Ferenc Herbert 


\section{Recommendations}

We listed a bunch of benefits and real problems of the renewable resources. We are convinced that the renewable approach is more than a fashion and it is more sustainable than the traditional fossil fuel operation. Some methods definitively help the promotion of these methods:

- prudent design of the systems

- enabling the remote control of the weather dependent production (limitation)

- diversification of sources in space

- development of the forecast precision

- VPP type aggregation centers

- cooperation with energy markets through developed info communication

\section{Conclusion}

The hydro, PV and wind energy production devices are off-the-shelf products that can be chosen from catalogues. The behavior of these tools really differs from the previous demand-controlled paradigm. It is high time for their application and integration. The good news is that several technical solutions exist for the large scale application of the weather dependent sources. The hot topics nowadays are the off-shore plants, the storage, the Demand Response Management.

\section{References}

[1] Immanuel Kant: Kritik der reinen Vernunft, 1781

[2] Peter Kadar: Seeking for the optimal market; 4th Slovakian - Hungarian Joint Symposium on Applied Machine Intelligence; Herl'any, Slovakia January 20-21, 2006, proceedings pp 234-246

[3] Peter Kadar: Scheduling of the generation of Renewable Power Sources; $5^{\text {th }}$ Slovakian - Hungarian Joint Symposium on Applied Machine Intelligence, Poprad, Slovakia January 25-26, 2007, proceedings pp 255-263

[4] Peter Kadar: Storage optimization in a liberalized energy market; 7th International Symposium on Applied Machine Intelligence and Informatics; Herl'any, Slovakia January 30-31, 2009

[5] Hugo Morais, Péter Kádár, Pedro Faria, Zita A. Vale, H.M. Khodr: Optimal scheduling of a renewable micro-grid in an isolated load area using mixedinteger linear programming; Elsevier Editorial System(tm) for Renewable Energy Magazine Volume 35, Issue 1, Pages 151-156; April, 2010

[6] Khodr, H.M.; Vale, Zita A.; Ramos, Carlos; Soares, J.P.; Morais, H.; Kadar, Peter: Optimal methodology for renewable energy dispatching in islanded operation; Transmission and Distribution Conference and 
Exposition, 2010 IEEE PES Digital Object Identifier: 10.1109/TDC.2010.5484411

[7] Peter Kadar: Power generation portfolio optimization by externality minimization; Acta electrotechnica et informatica; Faculty of Electrical Engineering and Informatics, Technical University of Kosice, SK; AprilJune 2010, vol.10. No.2, 2010, ISSN 1335-8243, pp5-9

[8] Peter Kadar: Multi Objective Power Mix Optimization; 8th International Symposium on Applied Machine Intelligence and Informatics (SAMI 2010) Herl'any, Slovakia January 28-30, 2010

[9] Zita Vale: "Computational Intelligence Applications for Future Power Systems", Computational Intelligence for Engineering Systems, 2011

[10] P. Kádár: Large Scale Wind Turbines and Their Application in Renewable energy systems Editor: Socrates Kaplanis - Eleni Kaplanis pp 405-452; Nova Science Publisher Inc. New York, 2013 ISBN: 978-1-62417-744-6

[11] Tiberiu Tudorache, Liviu Kreindler: Design of a Solar Tracker System for PV Power Plants; Acta Polytechnica Hungarica Vol. 7, No. 1, 2010

[12] Zerhouni et al,: Proposed Methods to Increase the Output; Efficiency of a Photovoltaic (PV) System; Acta Polytechnica Hungarica Vol. 7, No. 2, 2010

[13] P. Kadar, A. Varga: Measurement of spectral sensitivity of PV cells; Intelligent Systems and Informatics (SISY), 2012 IEEE 10th Jubilee International Symposium Subotica, Serbia, pp. 549 - 552, Sept 20-22, 2012 